\title{
The Effects of Spray Cooling on the Ceiling Gas Temperature at the Door Opening of Room Fires
}

\author{
HONG-ZENG YOU, HSIANG-CHENG KUNG, and ZHANXIAN HAN* \\ Factory Mutual Research Corporation \\ 1151 Boston-Providence Turnpike \\ Norwood, Massachusetts 02062, USA
}

\section{ABSTRACT}

A series of 3 freeburn and 22 sprinklered fire tests was conducted to investigate cooling in room fires by sprinkler spray. The tests were conducted in a $3.66 \mathrm{~m} \times 7.32 \mathrm{~m} \mathrm{x} 2.44 \mathrm{~m}$ high test room, which had a $1.22 \mathrm{~m}$ $\mathrm{x} 2.44 \mathrm{~m}$ high door opening centered in one of the $3.66 \mathrm{~m}$ walls. The fire source was a spray fire with constant heptane flow rate, located opposite the room opening. In each test, only one sprinkler was installed at the ceiling. Three geometrically similar sprinklers with nozzle diameters of $11.1 \mathrm{~mm}, 8.36 \mathrm{~mm}$, and $6.94 \mathrm{~mm}$ were tested.

The gas temperatures inside the test room were measured at selected locations. In addition, the convective heat flux leaving the door opening and the total heat release rate of the fire were measured with a fire products collector. The heat loss rate to the walls and ceiling was measured, as well as radiative heat loss through the opening. Empirical correlations for the bulk gas temperature of the hot gas flowing out from the door opening were established for both freeburn and sprinklered fire tests conducted in this study. Used with the previously established spray cooling correlations [2], the new correlations can predict the bulk gas temperature of the hot gas at the door opening for freeburn and sprinklered room fires.

KEY WORDS: Spray Cooling, Sprinklers

\section{INTRODUCTION}

As a fire develops in a room, combustion products generated from the fire tend to fill first the upper region inside the room, forming a hot gas layer beneath the ceiling. As the ceiling gas layer becomes thicker and hotter, radiation from the fire and hot ceiling gas layer may cause ignition of other combustibles in the room and may lead to fire flash-over eventually.

Recently, automatic sprinklers have gained considerable acceptance in health care facilities, hotels and residences. During a fire situation, if the first actuated sprinkler can suppress the fire and cool the hot ceiling gas layer sufficiently, unnecessary actuation of sprinklers remote from the fire source can be prevented. Consequently, water demand for the sprinkler system will be small, and the cost of the system can be reduced. Additionally, since the ceiling gas temperature is reduced by the

\footnotetext{
*Visiting scientist from Tianjin Fire Research Institute, Tianjin, China.
} 
sprinkler spray, ignition of other combustibles and the devastating flashover can also be prevented. Therefore, in order to design effective sprinkler protection, we need to know the relationship between sprinkler spray cooling and the reduction of hot ceiling gas layer temperature of room fires.

Kung [1] and You et al [2] conducted experimental studies on spray cooling of room fires. The same geometrically similar sprinklers were used in these two studies. In each fire test, only a single pendent sprinkler was installed inside the test room. In Kung's study, the test room was $3.05 \mathrm{~m} \times 3.66 \mathrm{~m} \times 2.44 \mathrm{~m}$ high. A hexane pool fire was located in the corner of the room, opposite the window opening. The heat absorption rate of sprinkler spray was directly proportional to heat release rate and sprinkler discharge rate, and varied as the -0.73 power of median drop size. In the study of you et al, the test room was $3.66 \mathrm{~m} \times 7.32 \mathrm{~m} \mathrm{x}$ $2.44 \mathrm{~m} \mathrm{high}$. The fire source was a spray fire with constant heptane flow rate. The fire source was located close to one wall, equidistant from the adjacent two orthogonal walls, and opposite the door opening. In addition to the correlation variables used in Kung's work, You et al included the variables of room opening size and heat loss rate from the room in the correlation with heat absorption rate by sprinkler spray. Within correlation limits, they successfully correlated both their own and Kung's heat absorption rate data. However, the corresponding reduction of ceiling layer gas temperature could not be assessed from their heat absorption rate correlations.

In the experiments conducted by You et al [2], the gas temperature inside the room was measured. The objective of this paper is to relate the ceiling gas temperature with the fire size $\left(Q_{a}\right)$, heat absorption rate of sprinkler spray $\left(Q_{c o o l}\right)$, and heat loss rate from room enclosure $\left(Q_{\ell}\right)$. Within correlation limits, $Q_{\mathrm{cool}}$ and $Q_{\ell}$ can be obtained from the previous spray cooling correlations for a fire size, room opening size and sprinkler operation conditions. From the results to be presented later in the paper, the ceiling layer gas temperature can be assessed for a fire size, opening size and sprinkler operation conditions in a room.

\section{EXPERTMENTAL SETUP}

In this study, the overall experimental setup plan included: a test room, a fire products collector, a fire source, geometrically similar sprinklers, heat flux sensors, pressure taps, and thermocouples. Except the thermocouples and pressure taps, the other items in the plan were described in detail in Reference 2. Therefore, in the following two sections, the thermocouples and pressure taps will be illustrated in detail; the remaining experimental setup will only be described briefly.

Test Room, Fire Products Collector, Fire Source, Sprinklers and Heat Flux Sensors

The test room $(3.66 \mathrm{~m} \times 7.32 \mathrm{~m} \times 2.44 \mathrm{~m}$ high) was built inside a large burn facility $(12.2 \mathrm{~m} \times 18.5 \mathrm{~m} \times 10.1 \mathrm{~m}$ high). A $1.22 \mathrm{~m}$ wide $\mathrm{x}$ $2.44 \mathrm{~m}$ high door opening was located at the center of the west wall (see Figure 1). The test room was framed with wood studs and joists. The walls and ceiling were constructed of $13 \mathrm{~mm}$ thick plasterboards; the spaces between the plasterboards were sealed with joint compound. 
A fire products collector was constructed over the door opening to collect the combustion gases exiting from the opening. Based on the gas concentrations ( $\mathrm{CO}, \mathrm{CO}_{2}, \mathrm{O}_{2}, \mathrm{H}_{2} \mathrm{O}$ and total hydrocarbon), gas temperature and gas velocity measured inside the collector, the total heat release rate of the fire and the convective heat flux at the door opening could be calculated [2].

The fire source was a spray fire with constant heptane flow rate. The fire source was located close to the east wall, and equidistant from the north and south walls as shown in Figure 1. A steel plate was used to shield the fire source from direct spray impingement [2].

Three geometrically similar sprinklers with orifice diameters of $6.94,8.36$ and $11.1 \mathrm{~mm}$ were used in this study [2]. In each test only one sprinkler was installed inside the test room, equidistant from the north and south walls and $1.82 \mathrm{~m}$ from the east wall. The sprinkler deflector was $0.10 \mathrm{~m}$ below the ceiling. A brass disk, with its center $0.08 \mathrm{~m}$ below the ceiling, was installed in the vicinity of the sprinkler nozzle to actuate the solenoid valve through a temperature controller when the disk temperature reached $100^{\circ} \mathrm{C}$ above its initial temperature. The disk had a diameter of $25.4 \mathrm{~mm}$ and a thickness of $0.41 \mathrm{~mm}$.

Surface heat flux sensors were used to determine the heat loss rate through the walls and ceiling. The sensors employed in this study were thin-foil heat flux gages and pairs of thermocouples [2]. The thermocouple pairs were used to measure the inside and outside wall surface temperatures. The wall heat flux was calculated by numerically solving the pertinent transient heat conduction equation with the inside and outside wall surface temperatures as boundary conditions.

A wide-angle radiometer was placed outside the door opening to measure the radiative heat flux through the opening. It was assumed that the heat loss to the floor was mainly due to radiation from the fire source. In order to estimate the radiative heat flux to the floor, the radiation source of the fire was considered as a point source at the flame center, and the radiation intensity of the fire was estimated from the radiometer measurement. The total radiation flux to the floor was thus calculated by integrating the directional radiation incidence throughout the floor area.

\section{Thermocouples and Pressure Taps}

A total of 30 thermocouples was installed at three stations to measure gas temperatures inside the room and in the door opening. The three stations were labeled $A, B$ and $C$ as shown in Figure 1. Bare-bead thermocouples were used, fabricated from 30 -gage $(0.25 \mathrm{~mm}$ wire dia.), inconel-sheathed, chromel-alumel thermocouple wire.

Stations $A$ and $B$ were arranged in the east-west centerplane of the room; Station $C$ was located $0.31 \mathrm{~m}$ from the south wall and $0.31 \mathrm{~m}$ from the west wall. There were ten thermocouples near Station $A$. Of the ten thermocouples, six were arranged vertically in the centerplane with distances from the floor of $0.61,1.22,1.83,2.29,2.36$ and $2.40 \mathrm{~m}$, respectively. The other four thermocouples were $0.08 \mathrm{~m}$ below the ceiling, and arranged symmetrically with respect to the centerplane, to monitor the symmetry of the ceiling gas flow inside the room. Stations $B$ and $C$ each had a vertical thermocouple rack. Each rack had ten thermocouples, with elevations of $0.92,1.22,1.37,1.53,1.68,1.83,1.98,2.13,2.29$ and $2.36 \mathrm{~m}$ from the floor. 
In addition, two thermocouples were located outside the test room, near the southwest corner at $2.13 \mathrm{~m}$ and $0.31 \mathrm{~m}$ above the floor. These two thermocouples were used to monitor the vertical variation of ambient temperature from the floor level to the ceiling level of the room.

Near the southwest comer, pressure taps were located on the inside and outside surfaces of the west wall, to measure pressure differences between inside and outside of the room. Two pairs of pressure taps were used: one was at $0.31 \mathrm{~m}$ above the floor; the other was at $2.13 \mathrm{~m}$ above the floor. The pressure difference for each pair of pressure taps was measured with an electronic manometer (Datametrics Model 1173 Baroce11).

All data signals were monitored by a data acquisition system with a HP2100A computer. Every $2 \mathrm{~s}$ the system scanned each data channel five times and logged the average values of five readings on a magnetic disk.

\section{DATA ANALYSIS AND RESULTS}

A series of 3 freeburn and 22 sprinklered fire tests was conducted in this study. The major test variables included fire size, sprinkler orifice size, and water discharge rate. A summary of the test conditions is provided in Table I of Reference 2 .

For the fire tests with sprinkler sprays, the sprinkler actuated after a time lapse of $5 \mathrm{~s}$ to $35 \mathrm{~s}$ from ignition, depending on fire size. For each test, the measurements used for analysis were taken within a period of $80 \mathrm{~s}$ after the gas phase inside the room reached a steady state. The beginnings of the $80-\mathrm{s}$ periods are tabulated in Table $I$ of Reference 2.

\section{Correlations of Spray Cooling Data}

In Reference 2, heat absorption rate of sprinkler spray ( $Q_{\text {cool }}$, kW) and convective heat flux at the room opening $\left(Q_{c}, k W\right)$ were correlated with the fire size $\left(Q_{a}, \mathrm{~kW}\right)$, heat loss rate from the room enclosure $\left(Q_{\ell}, \mathrm{kW}\right)$, room opening area $\left(\mathrm{A}, \mathrm{m}^{2}\right)$ and height $(\mathrm{H}, \mathrm{m})$, and sprinkler operation conditions. The sprinkler operation conditions were determined by water pressure $(\Delta \mathrm{P}, \mathrm{kPa})$, water discharge rate ( $\mathrm{W}$, liters/min) and sprinkler orifice diameter $(D, m)$. The heat loss rate from the room enclosure was the sum of heat loss rate to the walls and ceiling, heat loss rate to the floor and radiative heat loss rate through the opening. For the reader's convenience, the correlation equations are presented here:

$$
\begin{aligned}
& Q_{\text {cool }} / Q_{a}=0.000039 \Lambda^{3}-0.003 \Lambda^{2}+0.082 \Lambda, \\
& Q_{c} / Q_{a}=0.67 \exp (-0.08 \Lambda),
\end{aligned}
$$

and

$Q_{\mathrm{a}}=Q_{\mathrm{cool}}+\mathrm{Q}_{\mathrm{c}}+\mathrm{Q}_{\ell}$

where $\Lambda=\left(A H^{1 / 2} Q_{\ell}\right)^{-1 / 2}\left(W^{3} \Delta \overline{p D}-2\right)^{1 / 3}, \Delta \bar{p}=\Delta p(k P a) /(17.2)$ and $D=D(m) /(0.0111)^{l}$.

Eqs. (1) and (2) were established from the data of room geometry with length-to-width ratio of $1.2-2.0$ and opening size of $1.70-2.97 \mathrm{~m}^{2}$. For no spray conditions, the ratio of $Q_{c}$ versus $Q_{a}$ is about $0.58-0.70$ in 
the study. However, as mentioned in Reference 2, we expect the ratio, $Q_{c} / Q_{a}$, for freeburn conditions to be different from the above values if the room conditions are drastically different from those specified above. For extreme room conditions, the $Q_{c} / Q_{a}$ ratio may approach zero if a room's length to width ratio is large, $i . e ., Q_{\ell}=Q_{a}$; on the other hand, the ratio may approach one if the room is completely insulated, $1 . e$. $Q_{\ell}=0$.

Within the correlation limits, the values of $Q_{c o o l}, Q_{c}$ and $Q_{\ell}$ can be solved from Eqs. (1) - (3) for a fire size and selected sprinkler operation conditions.

The Hot-Ceiling-Gas-Layer Thickmess at the Door Opening

The thickness of the hot gas layer at the room opening is defined as the distance between the ceiling and the "neutral plane" ( $h, m)$. The neutral plane is a gas layer boundary above which the hot gas leaves the room and below which cold ambient air enters the room. The methodology to determine the neutral plane location from the vertical gas temperature profile and the pressure difference between the inside and outside near the opening was developed by Quintiere and Denbraven [3].

Since the mean gas velocity at the neutral plane is zero, the stagnation pressure inside the room balances the outside amblent pressure at the level of the neutral plane. Figure 2 schematically depicts the gas flows and the vertical variations of stagnation pressure inside and outside the room. In the figure, $H, Z_{n}$, and $Z_{t}$ denote the distances measured from the floor to the ceiling, to the neutral plane, and to the elevation of discontinuity of gas temperature inside the room.

Referring to Eigure 2, the difference between the pressures inside and outside the door opening at an elevation above the neutral plane is:

$$
\Delta P_{i 01}=\int_{0}^{y}\left(\rho_{0}-\rho_{i}\right) g d y \text {, }
$$

where $\rho_{0}$ and $\rho_{i}$ denote the gas density outside and inside the room, respectively.

Similarly, the pressure difference at the elevation of $y_{2}$ above the neutral plane is

$$
\Delta \mathrm{P}_{i o 2}=\int_{0}^{\mathrm{y}}\left(\rho_{0}-\rho_{i}\right) \mathrm{g} d y \text {. }
$$

Therefore

$$
\Delta \mathrm{P}_{102}=\Delta \mathrm{P}_{101}+\int_{y_{1}}^{\mathrm{y}_{2}}\left(\rho_{0}-p_{1}\right) \mathrm{g} d \mathrm{y} .
$$

For the tests conducted in this study, the variation of ambient temperature from the floor level to the ceiling level was small. Therefore, for each test, $\rho_{O}$ can be replaced by the ambient density, $\rho_{\infty}$, which is constant from the floor level to the ceiling level.

Equation (6) thus becomes

$$
\Delta \mathrm{P}_{102}=\Delta \mathrm{P}_{101}+\rho_{\infty} \mathrm{g} \int_{\mathrm{y}_{1}}^{\mathrm{y}} \frac{\Delta \mathrm{T}}{\mathrm{T}_{\mathrm{i}}} \mathrm{dy} \text {. }
$$


If $\Delta \mathrm{T}_{10}$ and $\Delta \mathrm{T}_{j}$ 2 represent the temperature differences at level $\mathrm{y}_{1}$ and level $\mathrm{y}_{2}$ respectively, the temperature differences between $\mathrm{y}_{1}$ and $\mathrm{y}_{2}$ may be linearly interpolated from $\Delta \mathrm{T}_{101}$ and $\Delta \mathrm{T}_{102}$ by

$\Delta T=\Delta T_{101}+\left(\Delta T_{102}-\Delta T_{101}\right)\left(y-y_{1}\right) /\left(y_{2}-y_{1}\right)$.

Substituting Eq. (8) into Eq. (7) and letting $C_{t}=\Delta T_{\text {io2 }}-\Delta \mathrm{T}_{\text {io } 1}$ and $\ell=y_{2}-y_{1}$, we obtain

$\Delta \mathrm{P}_{i 02}=\Delta \mathrm{P}_{i 01}+\rho_{\infty} \mathrm{gl}\left[1+\frac{\mathrm{T}_{\infty}}{\mathrm{C}_{\mathrm{t}}}\right.$ in $\left.\left(\mathrm{T}_{11} / \mathrm{T}_{12}\right)\right]$.

The location of the neutral plane corresponds to the level where $\Delta \mathrm{P}_{i 01}=0$. If there are $\mathrm{m}$ intervals between temperature measurements from the level $y_{2}$ to the neutral plane, based on Eq. 9 ,

$$
\Delta P_{i 02}=\sum_{m} \rho_{\infty} g \ell_{m}\left[1+\left(T_{\infty} / C_{t, m}\right) \text { ln }\left(T_{i 1, m} / T_{i 2, m}\right)\right]
$$

at the neutral plane. In $\mathrm{Eq} .(10), \Delta \mathrm{P}_{102}$ denotes the pressure difference measured at level $y_{2}$.

In this study, the elevation of the neutral plane was determined based on temperature measurements of the thermocouple rack located at Station $\mathrm{C}$ together with the measurements of pressure difference, $\Delta \mathrm{P}_{102}$, on the west wall $0.31 \mathrm{~m}$ below the ceiling.

The Centerplane Bulk Gas Temperature of the Hot Gas Layer at the Door opening

After determining the elevation of the neutral plane, we may calculate the centerplane bulk gas temperature of the hot gas layer above the neutral plane at the door opening, based on the measurements of the thermocouple rack at the door opening. The gas temperatures measured at Station $A, 0.08 \mathrm{~m}$ below the ceiling indicated that the ceiling gas temperature was symmetrical with respect to the room centerplane, and the maximum always occurred in the centerplane. Therefore, for each horizontal traverse of gas temperature across the door opening, the gas temperature in the centerplane was expected to be the maximum. opening is

The centerplane bulk gas temperature of the hot gas layer in the door $\Delta \mathrm{T}_{\mathrm{u}}=\mathrm{Q}_{\mathrm{c} \phi} / \dot{\mathrm{m}}_{\phi} \mathrm{C}_{\mathrm{p}}$

where $\dot{\mathrm{m}}_{\phi}$ and $Q_{\mathrm{c} \phi}$ are the mass flow rate and convective heat flux associated with the centerplane gas temperature and velocity of the hot gas layer at the door opening. $C_{p}$ is the air specific heat assumed to be constant.

At the room opening, we may horizontally divide the opening area above the neutral plane into parallel strips. These strips are delimited by horizontal lines whose heights are set at the same elevations as the thermocouples of the thermocouple rack in the door opening.

If the gas flow through the door opening is treated as orifice-like flow as described by Prahl and Emmons [4], $Q_{c \phi}$ and $m_{\phi}$ can be written as

$$
Q_{e \phi}=e C_{p} \sum_{i} C_{i}\left(2 \rho_{i} \Delta P_{i o, i}\right)^{1 / 2} \ell_{i} \Delta T_{i} \text {, }
$$


and

$$
\dot{m}_{\phi}=e \sum_{i} c_{i}\left(2 p_{i} \Delta p_{i o, i}\right)^{1 / 2} \ell_{i} .
$$

In Eqs. (12) and (13), e is the width of the door opening, $C_{i}$ and $\ell_{i}$ are the orifice coefficient and height of strip $i$, and $\rho_{i}$ and $\Delta T_{i}$ are the air density and excess gas temperature in strip i.

Assuming that $C_{i}$ is constant for all strips $E q .(11)$ can be written in the following form:

$$
\Delta \mathrm{T}_{u}=\frac{\sum_{i}\left(\Delta \mathrm{P}_{\text {io } i} / \mathrm{T}_{i}\right)^{1 / 2} \ell_{i} \Delta \mathrm{T}_{i}}{\sum\left(\Delta \mathrm{P}_{i 0, i} / \mathrm{T}_{i}\right)^{1 / 2} \ell_{i}} \text {, }
$$

where the ideal gas law has been applied.

For each strip $i$, the values of $\mathrm{T}_{i}, \Delta \mathrm{T}_{i}$ and $\Delta \mathrm{P}_{\mathrm{i}}$, $i$ were taken as the averages of their corresponding values at the upper and lower boundaries of the strip. The pressure difference at each boundary was calculated using Eq. (9). For the strip next to the ceiling, $\mathrm{T}_{i}, \Delta \mathrm{T}_{1}$ and $\Delta \mathrm{P}_{10}$, $\mathrm{i}$ were taken to be the values at its lower boundary.

For freeburn room fires, the excess gas temperature of the hot gas layer inside the room can be correlated by $[2,5]$.

$\Delta \mathrm{T} \propto \mathrm{Q}_{\mathrm{a}} \mathrm{Q}^{-1 / 2 / \mathrm{A}^{1 / 2} / \mathrm{H}^{1 / 4}}$

for a wide range of test conditions.

For fire tests with sprinkler spray, the convective heat flux at the door opening is the remainder of the total heat release rate of the fire after some heat has been lost through the room enclosure and absorbed by the sprinkler spray. Therefore, Eq. (15) may be generalized for sprinklered fire tests by including the heat absorption rate of the spray into the heat loss term of Eq. (15).

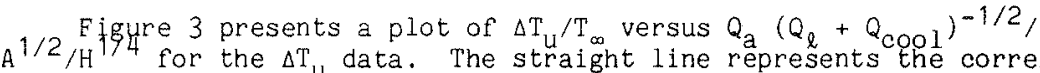
for three freeburn tests:

$\Delta \mathrm{T}_{\mathrm{u}, \text { freeburn }} / \mathrm{T}_{\infty}=-0.213+0.0544\left(\mathrm{Q}_{\mathrm{a}} \mathrm{Q}_{\ell}^{\left.-1 / 2 / \mathrm{A}^{1 / 2} / \mathrm{H}^{1 / 4}\right)}\right.$,

where $Q_{a}$ and $Q_{\ell}$ are in $\mathrm{kW}, A$ in $\mathrm{m}^{2}$, and $H$ in $\mathrm{m}$.

The fire sizes tested are grouped around three different nominal fire sizes $\left(Q_{2}\right)$. The fire sizes ranging from 396 to $494 \mathrm{~kW}, 246$ to $316 \mathrm{~kW}$ and 134 to $150 \mathrm{~kW}$ are represented by nominal fire sizes of 455,290 and 140 $\mathrm{kW}$, respeetively. For each nominal fire size, as shown in Figure 3 , the ratio of $\Delta \mathrm{T}_{\mathrm{u}}$ versus $\mathrm{T}_{\infty}$ tends to deviate from the correlation ine (solid line) of freeburn conditions if cooling is provided by the sprinkler spray. As more heat is absorbed by the spray greater deviation of $\Delta \mathrm{T}_{\mathrm{u}} / \mathrm{T}_{\infty}$ from the solid line is observed. The situation of $\Delta \mathrm{T}_{\mathrm{u}} / \mathrm{T}_{\infty}=0$ occurs when $Q_{a}=Q_{Q}+Q_{c o o l} ; i . e .$, the heat released by the fire is entirely dissipated through heat loss to the room enclosure and heat absorption by sprinkler spray. For the nominal fire sizes tested in the study, the
conditions of $\Delta \mathrm{T}_{\mathrm{u}} / \mathrm{T}_{\infty}=0$ correspond to $\mathrm{Q}_{\mathrm{a}}\left(\mathrm{Q}_{\ell}+\mathrm{Q}_{\mathrm{cool}}\right)^{-1 / 2} /\left(\mathrm{A} / \mathrm{H}_{\mathrm{H}}\right)=$ 
$Q_{a}^{1 / 2 / A^{1 / 2} / H^{1 / 4}}=5.49,7.90$ and $9.90 \mathrm{~kW}^{1 / 2} / \mathrm{m}^{5 / 4}$, respectively. Figure 3 indicates that the above predicted conditions agree with those extrapolated from the present data.

Based on Figure 3 , we may correlate the $\Delta T_{u}$ data for different nominal fire sizes with a single equation by normalizing the data of different spray conditions with respect to those of the corresponding freeburn tests. For each nominal fire size $Q_{a}$, the value of $Q_{a}\left(Q_{\ell}+\right.$

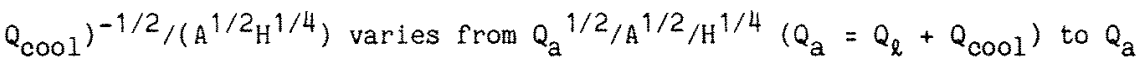
$Q_{e}{ }^{-1 / 2} / A^{1 / 2} / H^{1 / 4}$ (freeburn). The associated value of $\Delta \mathrm{T}_{\mathrm{u}}$ ranges from 0 to $\Delta T_{u}$ freeburn $/ T_{\infty}$. If the relative effect of spray cooling on the hot ceiling gas layer is similar among different fire sizes, the following function is expected to correlate the data:

$$
\Delta T_{u} / \Delta T_{u, \text { freeburn }}=f\left(\frac{Q_{a}{ }^{1 / 2}\left(Q_{\ell}+Q_{c o 0 l}\right)^{-1 / 2}-1}{Q_{a}{ }^{1 / 2} Q_{\ell, \text { freeburn }}{ }^{-1 / 2}-1}\right)
$$

For the sprinklered fire tests, their corresponding values of

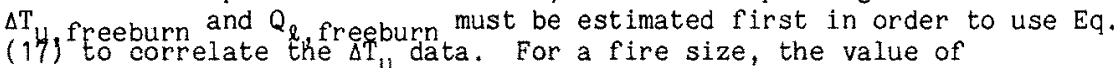
$\Delta T_{u, f r e e b u r n}$ was determined from $E q .(16)$; the value of $Q_{\ell}$, freeburn was determined from Eqs. (1) to (3) with $Q_{\text {cool }}=0$.

Figure 4 is a replot of the data presented in Figure 3, using the parameters illustrated in $\mathrm{Eq}$. (17). The functional relationship of Eq. (17) nicely collapses the $\Delta \mathrm{T}_{u}$ data into a single curve for both freeburn and spray conditions. The correlation curve shown in Figure 4 was formulated using the following equation:

$$
\Delta \mathrm{T}_{\mathrm{u}} / \Delta \mathrm{T}_{\mathrm{u}, \text { freeburn }}=\left(\frac{\mathrm{Q}_{\mathrm{a}}{ }^{1 / 2}\left(\mathrm{Q}_{\ell}+\mathrm{Q}_{\mathrm{cool}}\right)^{-1 / 2}-1}{\mathrm{Q}_{\mathrm{a}}{ }^{1 / 2 Q_{\ell}, \text { freeburn }}{ }^{-1 / 2}-1}\right)^{0.601}
$$

As indicated previously in this paper, Eq. (18) does not apply to cases where $Q_{\ell}=Q_{a}$ and $Q_{\ell}=0$.

\section{CONCLUSION}

Empirical correlations for the bulk gas temperature of the hot gas layer in the vertical centerplane at the door opening were established for both freeburn and sprinklered room fire tests conducted in this study. The bulk gas temperatures for the freeburn tests were correlated according to References 2 and 5 . The bulk gas temperatures for the sprinklered fire tests were correlated in terms of: 1) total heat release rate of fire; 2) heat loss rate to the room enclosure; 3) heat absorption rate of sprinkler spray.

Within the correlation limits associated with Eqs. (1) and (2), the heat loss rate to room enclosure and the heat absorption rate of sprinkler spray can be calculated from Eqs. (1) through (3) for a test condition. Therefore, the bulk gas temperature of the hot gas layer at the door opening can be readily calculated using Eqs. (16) and (18) for a fire size and sprinkler operation condition. The calculated hot-gas-layer bulk temperature is useful to assess the possibilities of actuation of remote sprinklers and ignition of remote combustibles in the same room and the ad jacent rooms. 


\section{ACKNOWLEDGEMENTS}

The valuable comments made by Dr. Gunnar Heskestad are sincerely appreciated.

\section{REFERENCES}

1. Kung, H.C., "Cooling of Room Fires by Sprinkler Spray," ASME Journal of Heat Transfer, Vol. 99, p. 353, 1977.

2. You, H.Z., Kung, H.C. and Han, 2., "Spray Cooling in Room Fires," The Twenty-First International Symposium on Combustion, Technical University of Munich, West Germany, August 3-8, 1986.

3. Quintiere, J.G., and DenBraven, K., "Some Theoretical Aspects of Eire Induced Flows Through Doorways in a Room-Corridor Scale Model," Center for Fire Research, National Bureau of Standards, NBSIR 78$1512,1978$.

4. Prahl, J., and Emmons, H.W., "Fire Induced Flow Through an Opening," Combustion and Flame, Vol. 25, p. 369, 1975.

5. McCaffrey, B.J., Quintiere, J.G., and Harkleroad, M.F., "Estimating Room Temperatures and the Likelihood of Flashover Using Fire Test Data Conditions," Fire Technology, Vol. 17, p. 98, 1981. 
AL DIOSIONS IN KETERS

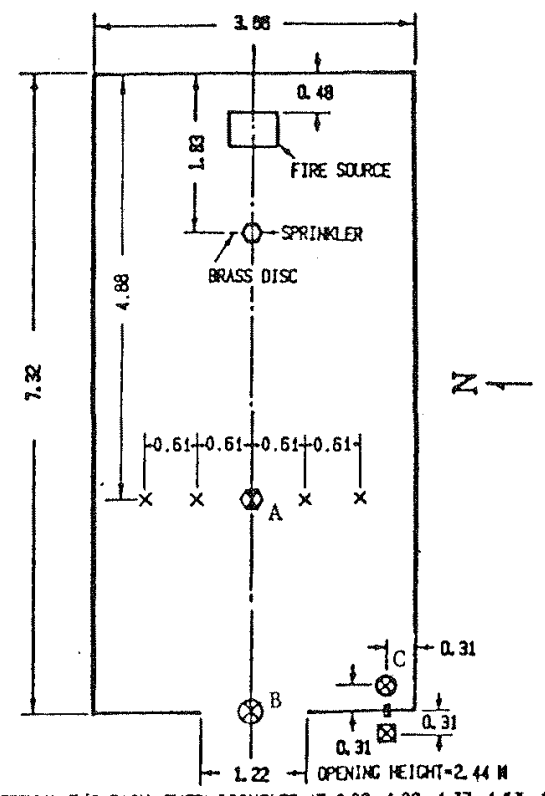

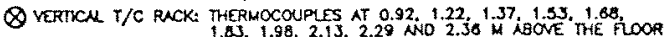

$\$$ VERTCN T/C RACK. THERMOCOUPLFS AT $0.61,1.22,1.83,2.29,2.36$

8 TWO THERMCCOUPLES: 0.31 ANO $2.13 \mathrm{H}$ ABONE THE FWOR

$X$ ONE THERMOCOUPLE: 0.08 W EROW THE CELUNC

Q THO DEFERENTLL PRESSURE IRANSOUCERS: 0.31 ANO 2.13 M ABONE

THE FLOR

Figure 1. Plane view of the test room and instrumentation layout inside the room enclosure. 


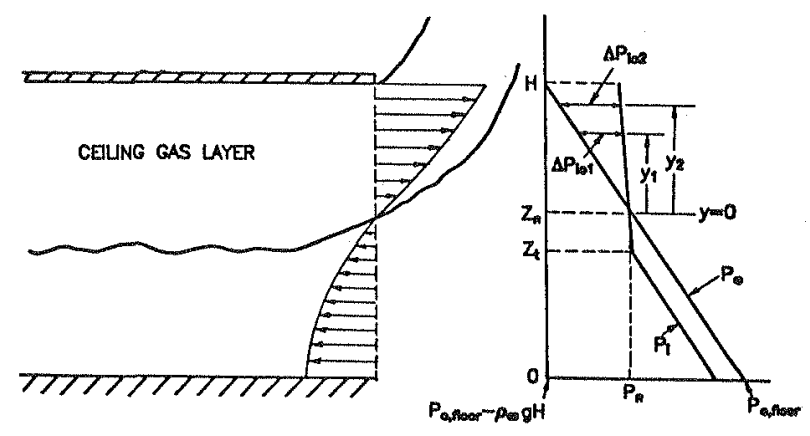

Figure 2. Pressure vartations inside and outside the door openings.

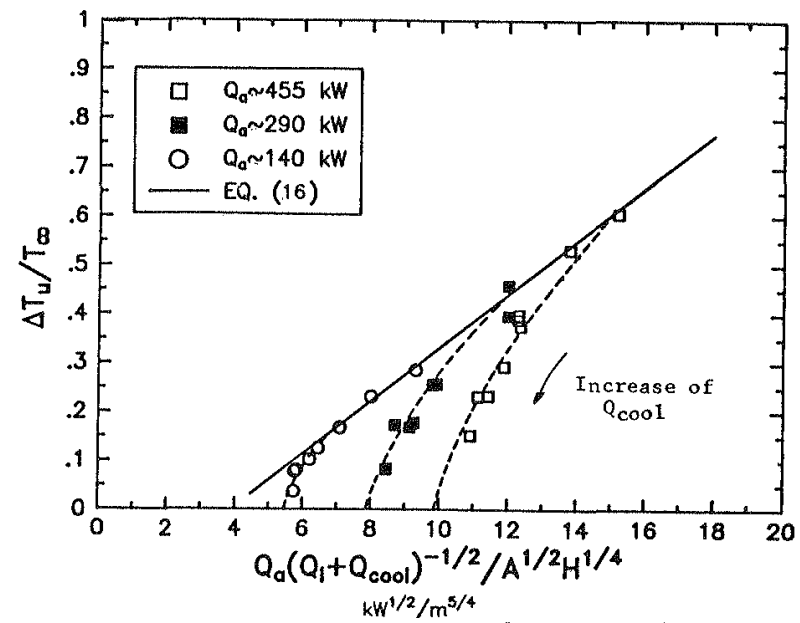

Figure 3. The bulk gas temperature of hot gas layer in the centerplane of the door opening.

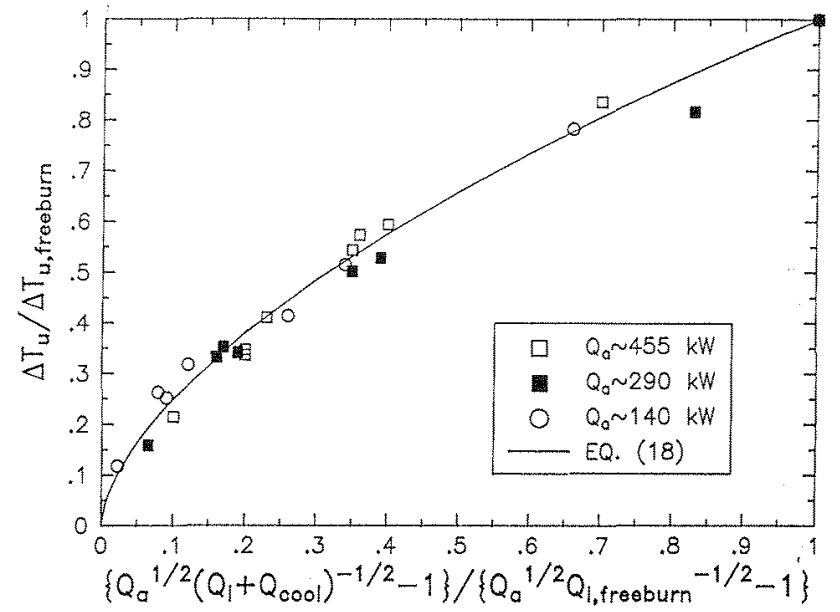

Figure 4. A replot of the data presented in Figure 3 using the functional parameters of Eq. (17). 
